\title{
Acute and chronic environmental effects of clandestine methamphetamine waste
}

\author{
Lisa N. Kates ${ }^{* 1}$, Charles W. Knapp, Helen E. Keenan \\ Department of Civil and Environmental Engineering, University of Strathclyde, 75 Montrose St., Glasgow, \\ G1 1XJ, United Kingdom \\ * Corresponding author \\ ${ }^{1}$ Present address: Intrinsik Environmental Sciences Inc. 736 8th Avenue SW, Suite 1060, Calgary, \\ Alberta, Canada, T2P $1 \mathrm{H} 4$ \\ Tel: +1.403.237.0275; E-mail address: 1kates@intrinsik.com
}

\begin{abstract}
The illicit manufacture of methamphetamine (MAP) produces substantial amounts of hazardous waste that is dumped illegally. This study presents the first environmental evaluation of waste produced from illicit MAP manufacture. Chemical oxygen demand (COD) was measured to assess immediate oxygen depletion effects. A mixture of five waste components (10 mg/L/chemical) was found to have a COD (130 mg/L) higher than European Union wastewater discharge regulations $(125 \mathrm{mg} / \mathrm{L})$. Two environmental partition coefficients, $K_{O W}$ and $K_{O C}$, were measured for several chemicals identified in MAP waste. Experimental values were input into a computer fugacity model (EPI Suite ${ }^{\mathrm{TM}}$ ) to estimate environmental fate. Experimental $\log K_{O W}$ values ranged from -0.98 to 4.91 , which were in accordance with computer estimated values. Experimental $K_{O C}$ values ranged from 11 to 72 , which were much lower than default computer values. The experimental fugacity model for discharge to water estimates waste components will remain in the water compartment for 15 to 37 days. Using a combination of laboratory experimentation and computer modelling, the environmental fate of MAP waste products was estimated. While fugacity models using experimental and computational values were very similar, default computer models should not take the place of laboratory experimentation.
\end{abstract}

\section{Keywords}

Environmental modelling; clandestine laboratories; methamphetamine waste; EPI Suite $^{\mathrm{TM}} ; K_{O W} ; K_{O C}$

Kates L.N., C.W. Knapp, H.E. Keenan (2014) Acute and chronic environmental effects of clandestine methamphetamine waste. Science of The Total Environment, 493: 781-788.

DOI: 10.1016/j.scitotenv.2014.06.066 


\section{Introduction}

The study of pharmaceutical products and illicit drugs in the environment rose to prominence in the early 2000s (Heberer, 2002; Jones-Lepp et al., 2004). Researchers discovered that these compounds are ubiquitous in river water, surface water, and wastewater (Glassmeyer et al., 2005; Huerta-Fontela et al., 2008; Kasprzyk-Hordern et al., 2009; Zuccato et al., 2008). As the world population and drug usage increases, it is expected that more of these products will be found in the aqueous environment. To date, most research has focused on detection of these contaminants. Research is lacking on the short term and long-term effects of these products in the environment, such as the adverse physiological and toxic effects on ecosystems and the persistence of drug residues in both water and sediments.

Synthetic drugs that are manufactured illicitly, such as amphetamine type stimulants (ATS), pose an additional risk to the environment from clandestine drug laboratories. Methamphetamine (MAP) is the most commonly produced ATS worldwide, typically manufactured in clandestine laboratories close to the consumer (UNODC, 2012). The illicit manufacture of MAP produces a large amount of harmful waste that is often dumped illegally, creating a potential source of pollution. One kilogram of MAP produces five to seven kilograms of waste that includes many volatile, flammable, and corrosive chemicals, as well as heavy metals (White, 2004). Common routes of disposal include poured down indoor plumbing, direct discharge into surface waters, or the waste being burned and/or buried (US EPA, 2005). However, illicit drug manufacturers are often not prosecuted for crimes related to polluting the environment due to the costs associated with prosecution and lack of research in this area.

To aid in the detection and prosecution of an illicit dumpsite, an understanding of the chemical behaviour of the waste components is essential. The fate of contaminants entering the environment is dependent on their physicochemical properties, such as hydrophobicity, vapour pressure, and stability (Walker et al., 1996). The use of partition coefficients in environmental modelling of organic chemicals is useful in predicting the behaviour of a contaminant in the environment, contaminants such as MAP waste. However, an environmental model is only as reliable as the information input into the scenario. Therefore, to generate the most reliable model as possible, it is essential to gain as much information about the dumpsite and the chemicals as feasible. Information that will aid the reliability of the model includes the organic carbon content of the dumpsite and partition coefficients of the waste components.

Two useful partition coefficients that are readily measureable in the laboratory are the octanol-water partition coefficient $\left(K_{O W}\right)$ and the organic carbon partition coefficient $\left(K_{O C}\right) . K_{O W}$ is a measure of the hydrophobicity of a compound, which is inversely related to polarity. Generally, as the hydrophobicity of a substance increases, so does its toxicity. The lipophilicity content that permits compounds to enter cell membranes is also linked to bioconcentration of organic substances in aquatic organisms. High $K_{O W}$ values are associated with high bioconcentration factors (BCF).

$K_{O C}$ is often referred to as the organic carbon normalized sorption constant, which is a measurement of the partitioning behaviour between water and the organic carbon fraction in a water-sediment system. The $K_{O C}$ value factors into account the percentage of organic carbon present in the sediment, which can greatly influence the amount of adsorption. 
While $K_{O W}$ and $K_{O C}$ values provide good information regarding the fate and long term consequences of an organic pollutant, short term changes may cause just as much if not greater harm. In order to assess the acute environmental impact of MAP waste, the chemical oxygen demand (COD) can be measured to determine possible oxygen depletion in receiving waters. COD is an indicative value of water and wastewater quality that measures the amount of oxygen consumed by organic pollutants through oxidation.

This paper aims to assess initial environmental fate and impact of organic waste products from clandestine MAP laboratories. This was undertaken using computer modelling in conjunction with laboratory testing.

\section{Methods}

\subsection{Target Compounds}

The target compounds selected for study were based on waste products identified in a preliminary profiling study (Kates et al., 2012). In the profiling study, organic waste was collected from in-house MAP synthesis following the Leuckart (Kunalan et al., 2009), hypophosphorous (Vallely, 2009), or Moscow (Kunalan et al., 2009) route. Not all of the compounds identified were available to purchase as analytical standards, which limited the number of compounds available for this current study. The MAP waste chemicals tested in this study are summarized in Table 1. All chemicals in this study were purchased as analytical grade standards from Sigma Aldrich, UK. Solvents were HPLC grade and all analyses were completed using high performance liquid chromatography with a UV detector. 
Table 1

General information on MAP waste compounds used in the current study

\begin{tabular}{|c|c|c|c|c|c|c|c|}
\hline $\begin{array}{l}\text { Target compound } \\
\text { full name } \\
\text { (CAS Number) }\end{array}$ & Abbreviation & $\begin{array}{l}\text { Synthetic } \\
\text { route }\end{array}$ & $\begin{array}{l}\text { Molecular } \\
\text { formula }\end{array}$ & $\begin{array}{l}\text { Molecular } \\
\text { weight }\end{array}$ & $\lambda \max (n m)$ & Molecular structure & $\begin{array}{l}\text { Property } \\
\text { measured }\end{array}$ \\
\hline $\begin{array}{l}\text { Methamphetamine } \\
(537-46-2)\end{array}$ & MAP & Final product & $\mathrm{C}_{10} \mathrm{H}_{15} \mathrm{~N}$ & 149.24 & 212 & & $\mathrm{COD}, K_{O W}, K_{O C}$ \\
\hline $\begin{array}{l}\text { Benzaldehyde, oxime } \\
(622-31-1)\end{array}$ & $\mathrm{BOX}$ & $\mathrm{L}$ & $\mathrm{C}_{7} \mathrm{H}_{7} \mathrm{NO}$ & 121.14 & 216 & & $\mathrm{COD}, K_{O W}, K_{O C}$ \\
\hline $\begin{array}{l}\text { Benzyl alcohol } \\
(100-51-6)\end{array}$ & $\mathrm{BA}$ & $\mathrm{L}, \mathrm{M}, \mathrm{H}$ & $\mathrm{C}_{7} \mathrm{H}_{8} \mathrm{O}$ & 108.14 & 212 & & $K_{O W}$ \\
\hline $\begin{array}{l}\text { 2,6-di-tert-butylphenol } \\
(128-39-2)\end{array}$ & 2,6-DTBP & $\mathrm{L}, \mathrm{M}, \mathrm{H}$ & $\mathrm{C}_{14} \mathrm{H}_{22} \mathrm{O}$ & 206.32 & 212 & & $K_{O W}, K_{O C}$ \\
\hline $\begin{array}{l}N \text {-methylacetamide } \\
(79-16-3)\end{array}$ & $N$-MA & $\mathrm{L}$ & $\mathrm{C}_{3} \mathrm{H}_{7} \mathrm{NO}$ & 73.09 & - & & $\mathrm{COD}, K_{O W}, K_{O C}$ \\
\hline $\begin{array}{l}\text { Phenol } \\
(108-95-2)\end{array}$ & PHE & $\mathrm{L}$ & $\mathrm{C}_{6} \mathrm{H}_{6} \mathrm{O}$ & 94.11 & 220 & & $\mathrm{COD}, K_{O W}, K_{O C}$ \\
\hline $\begin{array}{l}\text { 1-phenyl-2-propanone } \\
(103-79-7)\end{array}$ & $\mathrm{P} 2 \mathrm{P}$ & $\begin{array}{l}\text { L precursor } \\
\mathrm{H} \text { by-product }\end{array}$ & $\mathrm{C}_{9} \mathrm{H}_{10} \mathrm{O}$ & 134.17 & 208 & & $\mathrm{COD}, K_{O W}, K_{O C}$ \\
\hline $\begin{array}{l}\text { 1-phenyl-1,2-propanedione } \\
(579-07-7)\end{array}$ & 1-P-1,2-P & $\mathrm{L}$ & $\mathrm{C}_{9} \mathrm{H}_{8} \mathrm{O}_{2}$ & 148.16 & 216 & & $K_{O W}$ \\
\hline
\end{tabular}

L - Leuckart; M - Moscow; H - Hypophosphorous 


\subsection{Chemical Oxygen Demand, COD}

COD was determined using a commercially prepared reactor digestion test tube kit with a range of $0-1500 \mathrm{mg} / \mathrm{L}$ oxygen (Hach-Lange, UK). Samples were prepared according to the kit instructions and COD values were measured using a portable colorimeter (DR/850 Hach-Lange, UK). MAP, P2P, N-MA, PHE, and BOX were tested as individual compounds at concentrations from $1 \mathrm{mg} / \mathrm{L}$ to $100 \mathrm{mg} / \mathrm{L}$. Those five compounds were also tested as part of a mixture at concentrations from $0.01 \mathrm{mg} / \mathrm{L}$ to 100 $\mathrm{mg} / \mathrm{L} / \mathrm{chemical}$. Thus the final chemical concentrations in the mixture solution ranged from $0.05 \mathrm{mg} / \mathrm{L}$ to $500 \mathrm{mg} / \mathrm{L}$. Solutions were made up in Nanopure water (Barnstead Nanopure, ThermoFisher Scientific, UK). According to the kit manufacturer, the estimated detection limit of the COD method is $30 \mathrm{mg} / \mathrm{L}( \pm 16 \mathrm{mg} / \mathrm{L})$.

\subsection{Octanol-Water Partition Coefficient, $K_{O W}$}

$K_{O W}$ (Eq. 1) values were experimentally determined by reversed phase high performance liquid chromatography (RPHPLC) following the Organisation for Economic Co-operation and Development (OECD) standard method 117 (OECD, 1989). The HPLC used was a Dionex UltiMate 3000 with a C18 column (Techsphere5ODS, $25 \mathrm{~cm} \mathrm{x}$ $4.6 \mathrm{~mm}$ ) and a variable wavelength detector.

$$
K_{O W}=\frac{[\text { chemical concentration in octanol }]}{[\text { chemical concentration in water }]}
$$

High $K_{O W}$ values are associated with high BCFs (Eq. 2) as most aquatic organisms will uptake organic pollutants through passive diffusion.

$$
B C F=\frac{[\text { chemical concentration in biota }]}{[\text { chemical concentration in water }]}
$$

BCF has a linear relationship with $K_{O W}$, as shown in Eq. (3).

$$
\log B C F=a \log K_{O W}+b
$$

\subsection{Soils}

Three different artificial soils were prepared for the sorption experiments to provide a range of organic carbon content and to reduce matrix interferences from polluted site samples. Garden humus (B\&Q, UK), sand (Portland Builder's sand), and clay (WBB Minerals, UK) were mixed with silt collected from a stream in Calderglen Country Park, Glasgow, UK (5544'57.48"N, 4 8'34.40"W).

The moisture and organic carbon content of each soil was determined following ASTM Standard Method D2974 - 07a (ASTM, 2007). The $\mathrm{pH}$ was determined using a $1: 1(\mathrm{w} / \mathrm{v})$ slurry of water and sediment, which was stirred for 30 minutes, then left to stand for one hour before a $\mathrm{pH}$ reading was taken.

The composition and physical properties of each soil is shown in Table 2. Each soil is classified as sandy loom according to British Standard BS 3882:2007 (British Standards, 2007). 
Table 2 Composition and physical properties artificial soils

\begin{tabular}{llll}
\hline & Soil \#1 & Soil \#2 & Soil \#3 \\
\hline Sand & 41.56 & 58.17 & 78.85 \\
Silt & 5.55 & 7.29 & 9.41 \\
Clay & 2.79 & 3.65 & 4.70 \\
Humus & 50.10 & 30.89 & 7.04 \\
\hline pH & 5.39 & 5.50 & 5.77 \\
Moisture Content $\left(\%, 105^{\circ} \mathrm{C}\right)$ & 13.90 & 8.75 & 2.11 \\
TOC $\left(\%, 440^{\circ} \mathrm{C}\right)$ & 7.46 & 4.37 & 1.44 \\
\hline
\end{tabular}

2.5 Sediment-Water Partition Coefficient, $K_{d}$

$K_{d}$ values of selected MAP waste impurities were measured following ASTM standard method E1195 - 01 (ASTM, 2008). Sorption of MAP, N-MA, PHE, BOX, P2P, and 2,6-DTBP was measured by equilibrating them in a mixture of water and sediment at constant temperature $\left(20^{\circ} \mathrm{C} \pm 1^{\circ} \mathrm{C}\right)$ in the dark. The amount of chemical added was determined by taking into account its water solubility, predicted adsorption coefficient, and limit of detection (LOD) of the HPLC-UV method used to quantify the amount of chemical left in the aqueous phase (details below; LODs calculated following Miller and Miller, 2010). Initial estimate of each chemical's adsorption coefficient was determined using Eq. (4), which predicts $K_{O C}$ to within one order of magnitude (eq. 3 in ASTM, 2008).

$\ln K_{O C}=\left(-\ln W_{s}-0.01(M P-25)+15.1621\right) / 1.7288$

Where:

$\mathrm{W}_{\mathrm{S}}=$ water solubility, $\mathrm{mg} / \mathrm{mL}$

$\mathrm{MP}=$ melting point, ${ }^{\circ} \mathrm{C}$ (for liquids at $25^{\circ} \mathrm{C}, \mathrm{MP}=25$ )

Sediment to water ratios were calculated to achieve chemical sorption between $20-80 \%$. With a fixed aqueous volume of $10 \mathrm{~mL}$, the sediment to water ratios used were $1: 2,1: 3$, and 1:5. Using $20 \mathrm{~mL}$ glass universal bottles fitted with aluminium foil-lined caps, $1.0 \mathrm{~mL}$ of $1.0 \mathrm{mg} / \mathrm{mL}$ in water of MAP, $N$-MA, PHE, BOX, and P2P was added to the sediment. The volume was brought to $10 \mathrm{~mL}$ using Nanopure water (Barnstead Nanopure, ThermoFisher Scientific, UK), for a final concentration of $0.1 \mathrm{mg} / \mathrm{mL}$.

The concentration of 2,6-DTBP was less because of its lower water solubility. The water solubility of 2,6-DTBP is $2.5 \mathrm{mg} / \mathrm{L}$ at $25^{\circ} \mathrm{C}$, however one half of that concentration would not completely dissolve in water at $20^{\circ} \mathrm{C}$. As per the standard method, the solution was made up in $10 \%$ acetonitrile $(\mathrm{ACN}) .2 .0 \mathrm{~mL}$ of $1.25 \mathrm{mg} / \mathrm{L}$ of 2,6-DTBP was added to the vials, for a final concentration of $0.25 \mathrm{mg} / \mathrm{L}$.

The contents of the vials were mixed on a roller shaker for four hours. Vials were centrifuged at 4500 RPM for 10 minutes and the supernatant filtered using a membrane syringe filter $\left(0.45 \mu \mathrm{m}\right.$; Millex MF-Millipore $\left.{ }^{\mathrm{TM}}\right)$. The filtrate was added to $2 \mathrm{~mL}$ autosampler vials, to which bisphenol $\mathrm{A}(40 \mu \mathrm{L}$ of $1.0 \mathrm{mg} / \mathrm{mL}$ in methanol) was added as internal standard. While Bisphenol A (BPA) is often found in effluents, it is not related to the compounds of interest from a clandestine MAP laboratory. By selecting an internal standard unrelated to the chemicals of interest, cross contamination issues can be 
eliminated. The absence of BPA in the artificial soils was proven in blank sample runs. The analytical method used to quantify the $K_{O C}$ experiment was HPLC with a UV variable wavelength detector. Thus the internal standard required a chromophore and an elution time that would not interfere with the compounds of interest, as well as an elution time that would not significantly prolong the run time.

Samples were quantified using HPLC (Dionex UltiMate 3000) with a C18 column (25 cm x $4.6 \mathrm{~mm}$, Techsphere5ODS) and a variable wavelength detector. Wavelengths were set according to the $\lambda$ max in Table 1 . The mobile phase was a gradient of ACN and water as follows: $20 \% \mathrm{ACN}, 80 \% \mathrm{H}_{2} \mathrm{O}$ for one minute, increasing to $40 \% \mathrm{ACN} / 60 \%$ $\mathrm{H}_{2} \mathrm{O}$ over five minutes, and held for seven minutes for a total run time of 13 minutes.

$K_{d}$ was calculated using Eq. (5).

$$
K_{d}=\frac{G_{S} /_{B}}{C_{S}}
$$

Where:

$$
\begin{aligned}
& \mathrm{G}_{\mathrm{S}}=\text { total quantity of chemical sorbed to solids, } \mu \mathrm{g} \\
& \mathrm{B}=\text { oven-dry weight of solids, } \mathrm{g} \\
& \mathrm{C}_{\mathrm{S}}=\text { concentration of chemical in water, } \mu \mathrm{g} / \mathrm{mL}
\end{aligned}
$$

And where $\mathrm{G}_{\mathrm{S}}$ is determined from HPLC quantification as follows:

$$
\begin{aligned}
& \mathrm{G}_{\mathrm{S}}=\mathrm{G}_{\mathrm{A}}-\mathrm{T} \\
& \mathrm{G}_{\mathrm{A}}=\text { total quantity of chemical in control sample, } \mu \mathrm{g} \\
& \mathrm{T}=\text { total quantity of chemical left in water, } \mu \mathrm{g}
\end{aligned}
$$

\subsection{Organic Carbon Partition Coefficient, $K_{O C}$}

Using the organic carbon content of the three manufactured soils (Table 2), Eq. (6) gives $K_{O C}$ as a function of $K_{d}$.

$$
K_{O C}=\frac{K_{d} \times 100}{\% O C}
$$

Where:

$\% \mathrm{OC}=$ Percent organic carbon of soil/sediment

\subsection{Prediction of environmental fate - fugacity modelling}

A user-friendly and freely available fugacity model can be found in the United States Environmental Protection Agency's (US EPA) computer modelling program Estimation Programs Interface (EPI) Suite ${ }^{\mathrm{TM}}$ (US EPA, 2012). EPI Suite ${ }^{\mathrm{TM}}$ uses a Level III fugacity model, meaning it assumes the compartments (air, water, soil, and sediment) are homogeneous.

In the EPI Suite ${ }^{\mathrm{TM}}$ fugacity model, it is possible to alter the emission scenario. Emission values for each compartment were changed to create a model that simulates dumping of chemicals directly into a body of water. Default emissions values for each 
compartment (air, water, and soil) are $1,000 \mathrm{~kg} / \mathrm{hr}$. The emissions values in this work were changed to: air: $0 \mathrm{~kg} / \mathrm{hr}$, water: $1,000 \mathrm{~kg} / \mathrm{hr}$, soil: $0 \mathrm{~kg} / \mathrm{hr}$.

\section{Results and Discussion}

\subsection{Acute impact of MAP waste}

COD can be used as an evaluative tool on the immediate impact of chemical waste in the environment. Results of the COD tests on MAP waste are shown in Table 3 and Table 4 . The results are defined as amount $(\mathrm{mg})$ of oxygen consumed per litre of sample.

Table 3 COD of individual MAP waste chemicals (mg/L COD; $\mathrm{n}=2$ )

\begin{tabular}{c|ccccc|c}
\hline $\begin{array}{c}\text { [Chemical } \\
(\mathrm{mg} / \mathrm{L})\end{array}$ & MAP & P2P & $N$-MA & PHE & BOX & COD Sum \\
\hline 1 & BDL & BDL & BDL & BDL & BDL & BDL \\
50 & 106 & 141 & 190 & 127 & 137 & 701 \\
100 & 201 & 252 & 119 & 235 & 249 & 1056 \\
\hline
\end{tabular}

$\mathrm{BDL}=$ below commercial kit detection limit of $30 \mathrm{mg} / \mathrm{L}$

Table 4 COD of five MA waste chemicals in a mixture (mg/L COD; $\mathrm{n}=2$ )

\begin{tabular}{cc|c}
\hline $\begin{array}{c}\text { Individual [Chemical] } \\
(\mathrm{mg} / \mathrm{L})\end{array}$ & $\begin{array}{c}\text { Total [Chemical] } \\
(\mathrm{mg} / \mathrm{L})\end{array}$ & COD \\
\hline 0.01 & 0.05 & $35 \pm 35$ \\
0.1 & 0.5 & BDL \\
1 & 5 & BDL \\
10 & 50 & $130 \pm 4$ \\
100 & 500 & $1081 \pm 25$ \\
\hline
\end{tabular}

$\mathrm{BDL}=$ below commercial kit detection limit of $30 \mathrm{mg} / \mathrm{L}$

COD is an indirect measurement of oxygen consumption by organic and inorganic chemicals in water (US EPA, 2009). The addition of oxidisable contaminants into water systems can result in the depletion of dissolved oxygen concentration (Harrison, 2007), which has the potential to harm aquatic species.

The European Union legislated value for COD levels of chemicals discharged into the environment is $125 \mathrm{mg} / \mathrm{L}$ (Council of European Union Communities, 1991). For individual waste components (Table 3), this threshold is reached at concentrations of 50 $\mathrm{mg} / \mathrm{L}$ or $100 \mathrm{mg} / \mathrm{L}$. For the mixture of the five chemicals (Table 4), the legislated threshold is also exceeded at a total chemical concentration of $50 \mathrm{mg} / \mathrm{L}$. Comparing results from the individual chemicals to the results of the mixture, the MAP waste components do not display additive effects. At a chemical concentration of $100 \mathrm{mg} / \mathrm{L}$, the summation of COD from the individual components $(1056 \mathrm{mg} / \mathrm{L} \mathrm{COD})$ is comparable to the COD values of the mixture (1081 $\mathrm{mg} / \mathrm{L} \mathrm{COD})$. The difference is more pronounced at lower chemical concentrations: at $50 \mathrm{mg} / \mathrm{L}$ the sum of the individual components (701 $\mathrm{mg} / \mathrm{L} \mathrm{COD})$ is over five times higher than the COD results from the mixture $(130 \mathrm{mg} / \mathrm{L}$ COD). This result suggests that the mixture is less harmful than the individual components. With the exception of phenol, these chemicals have few legitimate uses and 
are more likely to be found in the environment as part of a mixture. The mixture is a better indication of a real-life dumpsite scenario.

While concentrations of MAP waste in the environment have not been explored through case study, concentrations of 10 to $100 \mathrm{mg} / \mathrm{L}$ are exceedingly low for environmental dumping. On many occasions, clandestine MAP manufacturers will stock pile waste before disposing of it. In such circumstances, several tons of waste may be discharged in one location over a short period of time. The COD results indicate that such an event has the potential to cause depletion in the amount of dissolved oxygen to such an extent that it would become harmful to aquatic organisms. In one case study in Canada, a clandestine drug laboratory was seized based on the discovery of dead fish in a nearby stream (Hugel, 2010). While it is probable that several factors likely contributed to the death of the fish, the COD results from this experiment indicate oxygen depletion is certainly a potential contributor.

\subsection{Chronic effects of MAP waste}

\subsection{1 $\mathrm{K}_{O W}$ and $B C F$}

Experimentally determined $\log K_{O W}$ values of MAP waste are compared with EPI Suite $^{\mathrm{TM}}$ computer estimated $\log K_{O W}$ values in Table 5. Once the $K_{O W}$ values were determined, it was possible to calculate BCFs based on the experimental $K_{O W}$ and computer estimated $K_{O W}$, also shown in Table 5.

Table 5 Experimental Log $K_{O W}$ values compare to the EPI Suite ${ }^{\mathrm{TM}}$ computer estimates and BCF values based on experimental or EPI Suite ${ }^{\mathrm{TM}} K_{O W}$

\begin{tabular}{lllll}
\hline \multirow{2}{*}{ Chemical } & \multicolumn{2}{c}{$\log K_{O W}$} & \multicolumn{2}{c}{ BCF } \\
\cline { 2 - 5 } & Experimental & EPI Suite $^{\mathrm{TM}}$ & Experimental & EPI Suite $^{\mathrm{TM}}$ \\
\hline MAP & 2.04 & 2.07 & 11.13 & 11.84 \\
BOX & 1.45 & 1.85 & 2.28 & 3.68 \\
BA & 1.40 & 1.10 & 2.27 & 1.55 \\
$2,6-D T B P$ & 4.91 & 4.92 & 626.7 & 639.0 \\
$N$-MA & -0.98 & -0.70 & 0.89 & 0.90 \\
PHE & 1.32 & 1.46 & 1.98 & 2.42 \\
P2P & 1.77 & 1.44 & 4.99 & 2.80 \\
$1-P-1,2-P$ & 1.71 & 1.11 & 5.23 & 1.95 \\
\hline
\end{tabular}

Generally, small molecules with low $K_{O W}$ values are more likely to be water soluble, whereas larger molecules with high $K_{O W}$ values are more likely to dissolve in lipids and adsorb to solids. High $K_{O W}$ values are also associated with increased bioconcentration, which is linearly related to $K_{O W}$, as seen in Eq. (3). $K_{O W}$, which is essentially a measurement of polarity, can help to predict distribution and persistence of a compound in the environment. Hydrophilic compounds tend to be dissolved and distributed throughout surface water; corollary lipophilic compounds tend to become associated with particulate matter, mostly sediments (Walker et al., 1996).

Comparison of the experimental values with the EPI Suite ${ }^{\mathrm{TM}}$ shows little variation. Given the range of $K_{O W}$ values and their reporting on a log scale, the experimental and computer estimated values are remarkably equivalent. The experimental and predicted $\log K_{O W}$ values of 2,6-DTBP were nearly identical, whereas 
the largest difference in values was for 1-P-1,2-P, with a difference of 0.60. Even though the $\log K_{O W}$ values are nearly equivalent over the log scale, the differences become more apparent when the log function is removed, which may affect environmental compartment distribution, as investigated in Section 3.4.

The chemicals examined from MAP waste display the following order of lipophilicity, from lowest to highest: $N$-MA $<$ PHE $<$ BA $<$ BOX $<1-\mathrm{P}-1,2-\mathrm{P}<\mathrm{P} 2 \mathrm{P}<$ MAP < 2,6-DTBP. Using the linear relationship between $K_{O W}$ and BCF (Eq.3), the same order can be applied towards the tendency of these chemicals to bioaccumulate in aquatic organisms.

The BCF values were estimated using the EPI Suite ${ }^{\mathrm{TM}}$ model (Table 5). As the estimates are dependent on $K_{O W}$ values, BCFs were calculated using both the default $K_{O W}$ values and the experimental $K_{O W}$ values. BAF values are expressed in L/Kg wet-weight of fish, which enables comparison between different species by normalizing for lipid content. If the percent lipid of the organism is known, this can be accomplished by dividing the wet weight $(\mathrm{L} / \mathrm{Kg})$ by percent lipid, resulting in a value with units of $\mathrm{L} / \mathrm{Kg}$ lipid weight.

Two chemicals, 1-P-1,2-P and P2P, exhibited notable increases in BCF when calculated using the experimental $\log K_{O W}$, which corresponds to an increase in the potential uptake of these chemicals in fish. The BCF of 1-P-1,2-P increased by over three-fold, from 1.952 to 6.337 , when calculated using the experimental log $K_{O W}$ value compared to the computer estimated $\log K_{O W}$ value. The uptake of P2P also increased when BCF was calculated based on the experimental $\log K_{O W}$ compared to the computer estimated $\log K_{O W}$, displaying a two-fold increase from 2.803 to 5.908 in BCF values.

MAP itself was predicted to be the second most lipophilic component of the MAP waste. If MAP were to bioaccumulate in the lipid layers of fish, it would be unlikely to enter into the blood stream of the organism, meaning MAP would not cross the bloodbrain barrier and would not have the same physiological effects as an organism that ingested the drug directly. However, other behavioural or toxic effects may occur as the pollutant is slowly released into the general circulation. Ghazilou and Ghazilou (2011) observed that male fish had increased sexual activity when placed in a fiberglass aquarium with concentrations of MAP ranging from 0.1 to $1.0 \mathrm{mg} / \mathrm{L}$. Changes were observed after 2 and 5 days of exposure. However after 7 days of exposure there was a significant decrease in sexual activity, suggesting the fish grew acclimatised to their environment and adapted to the dopaminergic effects of the drug.

$\mathrm{K}_{\mathrm{OW}}$ values can be greatly influenced by $\mathrm{pH}$, as described in Bangkedphol et al., 2009 and Wells, 2006.

\subsubsection{Sorption of MAP waste onto sediment}

Sediment properties have a great influence over the behaviour of chemicals in the environment. The extent of adsorption of a chemical onto sediment is an important factor in determining the ultimate fate of chemicals in the environment. Adsorption is affected by a number of soil properties, such as organic matter content, clay content, and $\mathrm{pH}$. The extent of adsorption is also affected by the physicochemical properties of the compound, such as water solubility and $K_{O W}$ (Drillia et al., 2005). The physical properties of the artificial topsoils used in adsorption experiments are shown in Table 2.

Of the six target compounds studied in the $K_{O C}$ experiment, only four $K_{O C}$ values were able to be determined accurately. For MAP, matrix interferences prevented the 
resolution of a peak in the HPLC chromatogram. The lambda max of MAP was previously determined to be $212 \mathrm{~nm}$, which corresponds to many compounds present in soil, such as humic matter. The elution time of MAP also corresponded to the elution of humic matter despite numerous program optimization attempts. Using an HPLC equipped with a UV detector, it was not possible to separate MAP from soil matrix interferences. The other compound that could not be quantified on the HPLC was 2,6DTBP. Due to its low water solubility and high hydrophobicity, final water concentrations were below the limits of detection. Limits of quantification for the HPLC method are as follows (calculated as per Miller and Miller, 2010): $N$-MA $=34 \mu \mathrm{g} / \mathrm{L}, \mathrm{P} 2 \mathrm{P}$ $=5 \mu \mathrm{g} / \mathrm{L}, \mathrm{PHE}=5 \mu \mathrm{g} / \mathrm{L}, \mathrm{BOX}=4 \mu \mathrm{g} / \mathrm{L}$.

$K_{d}$ and $K_{O C}$ were calculated using Eqs. (5) and (6), shown in Table 6.

Table 6 Experimentally determined $\log K_{O C}$ and $K_{O C}$ values for MAP waste components

\begin{tabular}{lllll}
\hline & $N$-MA & P2P & PHE & BOX \\
\hline Soil 1 & 0.86 & 1.65 & 1.44 & 1.81 \\
Soil 2 & 1.07 & 1.69 & 1.56 & 1.88 \\
Soil 3 & 1.20 & 1.85 & 1.61 & 1.90 \\
\hline Average & 1.04 & 1.73 & 1.54 & 1.86 \\
\hline$K_{O C}$ & 10.96 & 53.70 & 34.67 & 72.44 \\
\hline
\end{tabular}

The $K_{O C}$ value represents the chemical's propensity to adsorb to organic carbon. The $K_{O C}$ is calculated from $K_{d}$ to be independent of sediment organic carbon content.

The ASTM method makes the assumption that the main factor affecting adsorption for non-polar organic chemicals is the organic carbon content of the sediment. In this study, the chemicals under investigation are fairly polar. In this case, other sediment properties may have greater effect on the adsorption behaviour. Other factors include physical forces, chemical forces, hydrogen bonding, hydrophobic bonding, electrostatic bonding, coordination reactions, and ligand exchanges (Tan, 1998). Adsorption of organic chemicals onto sediment surfaces is also influenced by several physicochemical properties of the chemical itself. Examples of those properties include the chemical nature of the adsorbate, water solubility, dissociation capacity, surface charge density, and polarity.

\subsection{Correlation between $\log K_{O C}$ and $\log K_{O W}$}

It has long been established that there is a linear relationship between $K_{O W}$ and $K_{O C}$ (US EPA, 1996). In an effort to predict $K_{O C}$ values for chemicals that were not tested, a plot was constructed of $\log K_{O W}$ versus $\log K_{O C}$ (Figure 1). Three lines are present on the plot: one line from experimental data and two lines from EPI Suite ${ }^{\mathrm{TM}}$ estimated values. EPI Suite ${ }^{\mathrm{TM}}$ uses two different methods of estimating $K_{O C}$. One method is based on $K_{O W}$ values (Eq. 7), the other based on molecular connectivity index (MCI, Eq. 8).

$$
\begin{aligned}
& \log K_{O C}=0.8679 \log K_{O W}-0.0004 \\
& \log K_{O C}=0.5213 M C I+0.62
\end{aligned}
$$




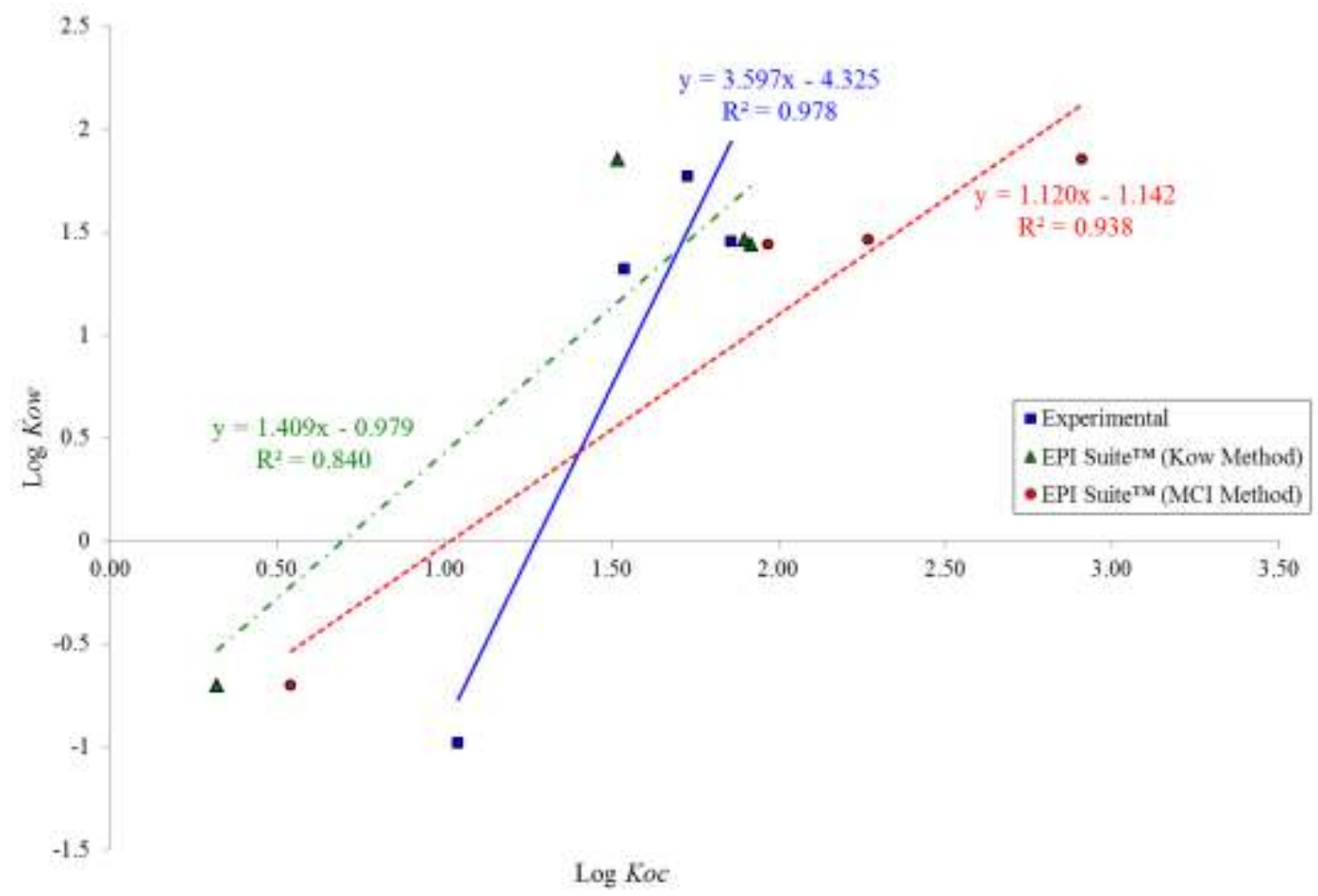

Figure 1 Correlation between $\log K_{O C}$ and $\log K_{O W}$

Looking at the correlation coefficients, the $\mathrm{R}^{2}$ value from the experimental data is closer to one $(0.978)$ than both EPI Suite ${ }^{\mathrm{TM}}$ values $(0.938,0.840)$, which indicates a stronger linear correlation. The poorest correlation between $\log K_{O C}$ and $\log K_{O W}$ is from the EPI Suite ${ }^{\mathrm{TM}}$ method that calculates $\log K_{O C}$ from $\log K_{O W}$. According to the EPI Suite ${ }^{\mathrm{TM}}$ methodology guide, $\log K_{O C}$ calculated from $\log K_{O W}$ has an $\mathrm{R}^{2}$ value of 0.877 $(\mathrm{n}=68)$, and an $\mathrm{R}^{2}$ value of $0.967(\mathrm{n}=69)$ when calculated using MCI.

Using the equation of the line from the experimental data (Eq. 9), it is possible to calculate $K_{O C}$ values for MAP, 2,6-DTBP, 1-P-1,2-P, and BA based on experimentally determined $K_{O W}$ values (Table 7).

$$
y=3.597 x-4.325
$$

Table $7 K_{O C}$ values calculated using experimental $K_{O W}$ values in Eq. (9)

\begin{tabular}{llll}
\hline Chemical & Exp. $\log K_{O W}$ & Calc. $\log K_{O C}$ & $K_{O C}$ \\
\hline MAP & 2.04 & 1.77 & 58.82 \\
BA & 1.40 & 1.59 & 39.05 \\
2,6-DTBP & 4.91 & 2.57 & 369.33 \\
1-P-1,2-P & 1.71 & 1.68 & 47.62 \\
\hline
\end{tabular}

3.4 Prediction of environmental fate

3.4.1 EPI Suite ${ }^{\mathrm{TM}}$ computer modelling 
Equipped with experimental partition coefficients, $K_{O C}$ and $K_{O W}$, environmental modelling using a fugacity model was conducted. As each model is only a reliable as the input data, it is important to have reliable input parameters.

Three different scenarios were run for each chemical - two using the default $K_{O C}$ and $K_{O W}$ values, the third using the experimental $K_{O C}$ and $K_{O W}$ values. The only other parameters altered were the emissions values, as described in section 2.7. Table 8 displays the compartment distribution from the fugacity model using $K_{O C}$ calculated from the default $K_{O W}$ value. Table 9 displays the compartment distribution using $K_{O C}$ calculated from MCI, and Table 10 is the compartment distribution from the fugacity model using experimental $K_{O C}$ and $K_{O W}$. 
Table 8

EPI Suite ${ }^{\mathrm{TM}}$ fugacity model using $K_{O C}$ calculated from default $K_{O W}$

\begin{tabular}{|c|c|c|c|c|c|c|c|c|c|c|c|c|c|c|c|c|}
\hline & \multicolumn{2}{|c|}{ BA } & \multicolumn{2}{|c|}{$\mathrm{P} 2 \mathrm{P}$} & \multicolumn{2}{|c|}{$N$-MA } & \multicolumn{2}{|c|}{ PHE } & \multicolumn{2}{|c|}{ MAP } & \multicolumn{2}{|c|}{ 1-P-1,2-P } & \multicolumn{2}{|c|}{ BOX } & \multicolumn{2}{|c|}{ 2,6-DTBP } \\
\hline$K_{o c}$ & \multicolumn{2}{|c|}{13} & \multicolumn{2}{|c|}{83} & \multicolumn{2}{|c|}{2} & \multicolumn{2}{|c|}{79} & \multicolumn{2}{|c|}{106} & \multicolumn{2}{|c|}{12} & \multicolumn{2}{|c|}{33} & \multicolumn{2}{|c|}{6506} \\
\hline $\log K_{O W}$ & \multicolumn{2}{|c|}{1.10} & \multicolumn{2}{|c|}{1.44} & \multicolumn{2}{|c|}{-0.70} & \multicolumn{2}{|c|}{1.46} & \multicolumn{2}{|c|}{2.07} & \multicolumn{2}{|c|}{1.11} & & 85 & \multicolumn{2}{|c|}{4.92} \\
\hline Air & 0 & 11 & 0.15 & 45 & 0 & 49 & 0 & 10 & 0.01 & 3 & 0 & 137 & 0 & 39 & 0.02 & 5 \\
\hline Water & 99.7 & 360 & 99.2 & 360 & 99.8 & 360 & 99.5 & 360 & 99.4 & 360 & 99.7 & 360 & 99.6 & 360 & 72.7 & 900 \\
\hline
\end{tabular}

$\%=$ Percent of chemical mass in specified compartment; $\mathrm{t}_{1 / 2}=$ half-life, hours

Table 9

EPI Suite ${ }^{\mathrm{TM}}$ fugacity model using $K_{O C}$ calculated from MCI

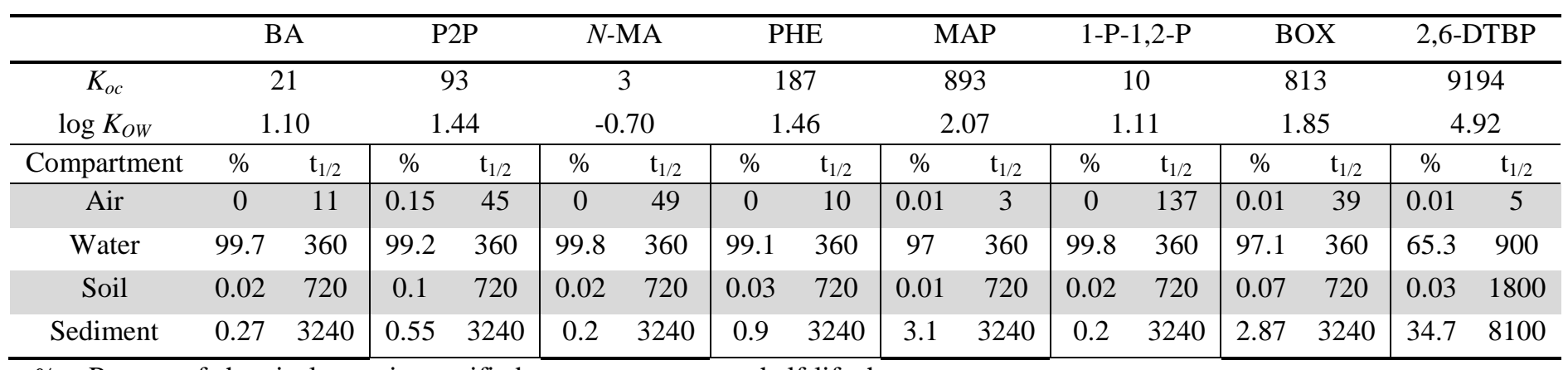

$\%=$ Percent of chemical mass in specified compartment; $\mathrm{t}_{1 / 2}=$ half-life, hours 
Table 10

EPI Suite ${ }^{\mathrm{TM}}$ fugacity model using experimental $K_{O C}$ and $K_{O W}$ values

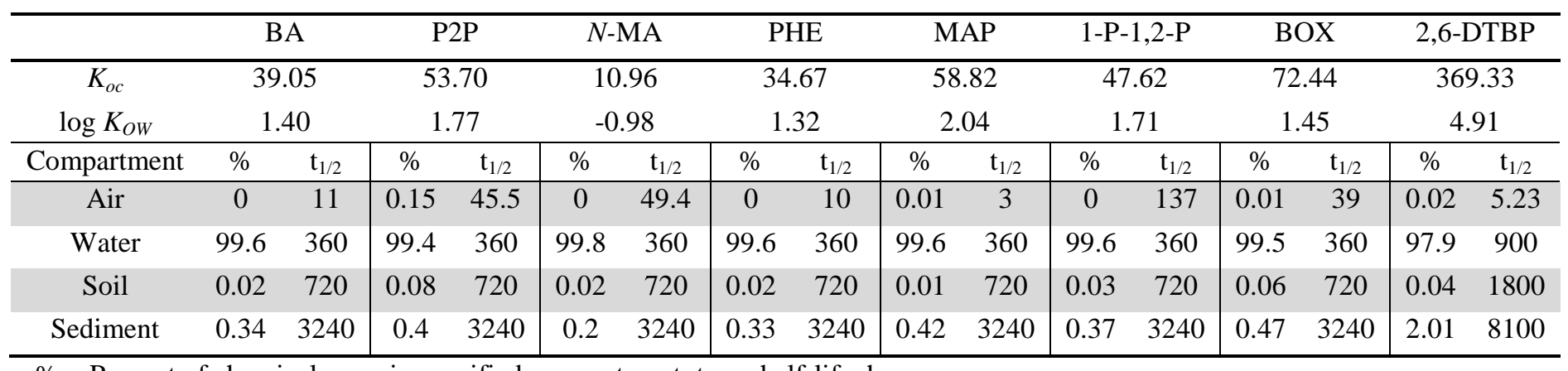

$\%=$ Percent of chemical mass in specified compartment; $\mathrm{t}_{1 / 2}=$ half-life, hours 
Since compartment distribution is dependent on the physicochemical properties of the chemicals, it is interesting to compare the three different fugacity models using three different sources of $K_{O C}$ and $K_{O W}$ values. For the model scenario of a simulated discharge into water, the fugacity model in all three instances indicates that seven of eight chemicals will overwhelmingly remain in the water compartment (97\%-99\%).

The $K_{O C}$ value will play a determining factor in the sediment-water partitioning. Looking at the $K_{O C}$ values from all three scenarios, the EPI Suite ${ }^{\mathrm{TM}}$ values calculated using $K_{O W}$ are within the same order of magnitude as the experimental $K_{O C}$ values. However, the EPI Suite ${ }^{\mathrm{TM}} K_{O C}$ values from MCI calculations are several orders of magnitude higher for MAP, BOX, and 2,6-DTBP. This change resulted in a difference in sediment-water distribution for MAP and BOX of 3\%. For 2,6-DTBP, there are greater disparities between each scenario in the sediment-water compartments. The distribution in the water compartment ranged from a high of $98 \%$ (Table 10) to a low of $65 \%$ (Table 9).

Even with the difference in $K_{O C}$ values, all the chemicals from MAP waste tested in this study will remain predominantly in the water compartment. This has implications for environmental sampling, indicating that water samples should be taken as opposed to sediment samples. The half-life of each chemical, except 2,6-DTBP, is predicted to be 15 days in the water compartment, with 2,6-DTBP having a half-life of 37.5 days. Given the transient nature of clandestine MAP laboratories, if a dumpsite is discovered after 15 days, there is a possibility the laboratory has already been dismantled.

Under controlled laboratory conditions, experimental $K_{O C}$ and $K_{O W}$ values corresponded closely to values calculated using the computer model EPI Suite ${ }^{\mathrm{TM}}$. In the absence of laboratory experimentation, the fugacity model that most closely represents experimental results is the model that uses $K_{O C}$ as calculated from $K_{O W}$. However, under environmental conditions, the partitioning behaviour may be different. Factors that can influence the $K_{O C}$ and $K_{O W}$ values are sediment properties, salinity, temperature and $\mathrm{pH}$, (Bangkedphol et al., 2009).

\subsubsection{Model assumptions}

EPI Suite ${ }^{\mathrm{TM}}$ has several assumptions and limitations that must be taken into account when interpreting the results. The model is designed to be a screening tool and should not be used if measured values are available. EPI Suite ${ }^{\mathrm{TM}}$ uses a Level III Fugacity model which has several assumptions of its own. The Level III model assumes steady state conditions, but not equilibrium conditions. This means the model assumes that chemical concentrations in each compartment will approach zero over time. The Level III model does not assume that each phase is in equilibrium, meaning that if a chemical is released into one compartment it can partition into the other compartments. In the Level III model, a chemical is continuously discharged at a constant rate and achieves a steady state condition when input and output rates are equal (CCEMC, 2002; US EPA, 2012).

Chemical losses occur through two methods: reaction and advection. Reactions include biotic or abiotic degradation of the chemical in each of the four compartments. Advection is the removal of a chemical from a compartment through losses other than degradation, such as bulk media transport via river currents. Advection processes are not considered for the soil compartment. Additional assumptions of the Level III model are 
that there are no direct emissions into the sediment compartment and it cannot model ionizing or speciating chemicals (CCEMC, 2002; US EPA, 2012).

There are several parameters that can be changed by the user in EPI Suite ${ }^{\mathrm{TM}}$ in order to create a chemical and site specific model; however, there are also numerous parameters that cannot be changed. For example, a fixed temperature of $25^{\circ} \mathrm{C}$ is assumed. That temperature will not reflect many countries mean annual temperatures, nor will it take into account daytime and seasonal variations.

While a site specific model can be approximated, the limitations in setting parameters will prevent a truly site specific model from being designed. This once again reinforces the need for laboratory experimentation, particularly in environments that vary considerably from the model default values. An additional limitation of the model is that mixtures cannot be evaluated. After understanding the assumptions and limitations of the EPI Suite ${ }^{\mathrm{TM}}$ fugacity model, its advantages are also important to note. Compared to other environmental models, such as a mass balance model, the fugacity model is easy to understand and it does not rely on units, but rather it is based on ratios therefore the units cancel out. In order to properly use a mass balance model, it is required to have estimated input concentrations of the chemicals. For this study, concentrations of MAP waste have never been measured or studied in a large scale, real-life scenario.

Previous research (Pal et al. 2011), measured the half-life value of MAP to range from 131 to 502 days, which is in contrast with the EPI Suite ${ }^{\mathrm{TM}}$ extimated value in soil of 30 days. In sediment, EPI Suite ${ }^{\mathrm{TM}}$ predicts a half-life of 135 days for MAP. The focus of this current study was MAP waste products, not necessarily MAP itself, in a sedimentwater system. The US EPA uses EPI Suite ${ }^{\mathrm{TM}}$ to evaluate new chemicals, to help estimate harmfulness and persistence in the absence of experimental data. The EPI Suite ${ }^{\mathrm{TM}}$ model calculates half-lives based on a combination of accumulated published data on 129 organic chemicals and correlation with 233 test chemicals using the computer model, developed by Mackay et al. (1999).

The Pal et al. (2011) study was conducted under ideal laboratory conditions. In a real-life dumpsite scenario, the chemicals will be exposed to environmental conditions, such as temperature fluctuations, precipitation, wind, etc. Without conducting a mockdumpsite experiment, it may not be feasible to determine an absolute half-life value. Additionally, each dumpsite will behave differently depending on the biological activity, environmental conditions and organic carbon content.

Computer models cannot replace experimental values, as shown by the difference in half-life values in this instance. However, in the absence of the ability to conduct yearlong experiments, a computer model can serve as a screening tool to flag chemicals that are estimated to be harmful to the environment.

\section{Conclusions}

By using a combination of laboratory experimentation and computer modelling, the environmental fate of MAP waste products was estimated. In the immediate term, the waste is likely to be harmful to aquatic organisms based on the amount of oxygen consumed through the oxidation reactions of the compounds. A mixture of the individual waste components was found to consume more oxygen than the individual chemicals. For longer-term implications in a discharge-to-water scenario, the waste is likely to remain in the water compartment and has a half-life of 15 to 37.5 days. The partitioning 
indicates that for suspected water dumpsites of MAP waste, water samples should be collected within two weeks in order to maximize detection. The analysis of sediment samples is not predicted to contain evidence of clandestine MAP waste.

From the experimental measurement of $K_{O C}$ and $K_{O W}$, a linear correlation was established. $K_{O W}$ can be measured very easily, while $K_{O C}$ experiments are time consuming and labour intensive. By using the correlation between the two partition coefficients, $K_{O C}$ can be estimated reliably through the measurement of $K_{O W}$. While fugacity models using experimental and computational values were very similar, default computer models should not take the place of laboratory experimentation.

\section{Acknowledgements}

The authors would like to thank Karl Bresee for a critical review of the manuscript and for providing valuable feedback regarding the EPI Suite ${ }^{\mathrm{TM}}$ model.

\section{References}

ASTM (American Society for Testing and Materials). Standard Test Method for Moisture, Ash, and Organic Matter of Peat and Other Organic Soils (Designation: D2974 - 07a), 2007.

ASTM (American Society for Testing and Materials). Standard Test Method for Determining a Sorption Constant (Koc) for an Organic Chemical in Soil and Sediments (Designation: E1195-01); 2008.

Bangkedphol S, Keenan H, Davidson C, Sakultanimetha A, Songsasen A. The partition behavior of tributyltin and prediction of environmental fate, persistence and toxicity in aquatic environments. Chemosphere 2009; 77 (10), 1326-1332.

British Standards. BS 3882:2007 Specification for topsoil and requirements for use, 2007.

CCEMC (Centre for Environmental Modelling and Chemistry). Level III model. http://www.trentu.ca/academic/aminss/envmodel/models/VBL3.html; March 2002 (last accessed May 14, 2014).

Council of European Union Communities. Directive 91/271/EEC. Official Journal of the European Communities, 1991.

Drillia P, Stamatelatou K, Lyberatos G. Fate and mobility of pharmaceuticals in solid matrices. Chemosphere 2005; 60, 1034-1044.

Glassmeyer ST, Furlong ET, Kolpin DW, Cahill JD, Zaugg SD, Werner SL, Meyer MT, Kryak, D. D. Transport of chemical and microbial compounds from known wastewater discharges: Potential for use as indicators of human fecal contamination. Environ Sci Technol 2005; 39 (14), 5157-5169.

Ghazilou A and Ghazilou S. Single and repeated exposure to methamphetamine induces altered sexual behavior in male sailfin molly (Poecilia latipinna Lesueur) (Pisces). Afr J Pharm Pharacol 2011; 5 (13), 1619-1622.

Heberer T. Occurrence, fate, and removal of pharmaceutical residues in the aquatic environment: a review of recent research. Toxicol Lett 2002; 131, 5-17.

Huerta-Fontela M, Galceran MT, Martin-Alonso J, Ventura F. Occurrence of psychoactive stimulatory drugs in wastewaters in north-eastern Spain. Sci Total Environ 2008; 397, 31-40.

Hugel J. Personal communication, Forensic Services Group, New South Wales Police Force; October 2010. 
Jones-Lepp TL, Alvarez D, Petty J, Huggins J. Polar Organic Chemical Integrative Sampling (POCIS) and LC-ES/ITMS for Assessing Selected Prescription and Illicit Drugs in Treated Sewage Effluents. Arch Environ Contam Toxicol 2004; 47(4), 427-439

Kasprzyk-Hordern B, Dinsdale RM, Guwy AJ. Illicit drugs and pharmaceuticals in the environment - Forensic applications of environmental data. Part 1: Estimation of the usage of drugs in local communities. Environ Pollut 2009; 157 (6), 17731777.

Kates LN, Gauchotte-Lindsay C, Nic Daéid N, Kalin RM, Knapp CW, Keenan HE. Prediction of the environmental fate of methylamphetamine waste. Environmental Forensics: Proceedings of the 2011 INEF Conference, Eds. Morrison, R.D.; O'Sullivan, G. RSC Publishing, Cambridge, UK., 262-274; 2012.

Mackay D, Shiu, WY, Ma KC. Physical-chemical properties and environmental fate handbook, CRC netBASE 1999 CD-ROM. Chapman and Hall/CRC Press: Boca Raton, FL US; 1999.

Meylan WM, Howard PH. Atom/fragment contribution method for estimating octanolwater partition coefficients. J Pharm Sci 1995; 84 (1), 83-92.

Miller JN, Miller JC. Statistics and chemometrics for analytical chemistry, $6^{\text {th }} \mathrm{Ed}$. Harlow, USA, Pearson Education Limited; 2010.

OECD (Organisation for Economic Co-operation and Development). Partition coefficient (n-octanol/water), high performance liquid chromatography (HPLC) method; March 1989.Pal R, Megharaj M, Kirkbride KP, Heinrich T, Naidu R. Biotic and abiotic degradation of illicit drugs, their precursor, and by-products in soil. Chemosphere 2011; 85 (6),1002-1009.

Tan KH. Principles of Soil Chemistry, 3rd Edition. Marcel Dekker, Inc; 1998.

UNODC (United Nations Office on Drugs and Crime). World Drug Report 2012,, Vienna, Austria; 2012

US EPA (United States Environmental Protection Agency). Soil Screening Guidance: Technical Background Document, Part 5: Chemical-Specific Parameters; 1996.

US EPA (United States Environmental Protection Agency). RCRA Hazardous Waste Identification of Methamphetamine Production Process By-products. Report to congress; 2005.

US EPA (United States Environmental Protection Agency). Drinking Water Glossary: A Dictionary of Technical and Legal Terms Related to Drinking Water. Office of Water/Office of Ground Water and Drinking Water; 2009

US EPA (United States Environmental Protection Agency). Estimation Programs Interface Suite for Microsoft Windows, v 4.11; 2012.

Valcárcel Y, Martínez F, González-Alonso S, Segura Y, Catalá Y, Molina R, MonteroRubio JC, Mastroianni N, López de Alda M, Postigo C, Barceló D. Drugs of abuse in surface and tap waters of the Tagus River basin: Heterogeneous photoFenton process is effective in their degradation. Environ Int 2012; 41, 35-43.

Vallely B. A Single Step Process for Methamphetamine Manufacture Using Hypophosphorous Acid. J Clandestine Lab Invest Chemists Assoc 2005; 5, 14-15.

Walker CH, Hopkin SP, Sibly RM, Peakall DB. Principles of Ecotoxicology. Taylor \& Francis, Bristol, UK; 1996. 


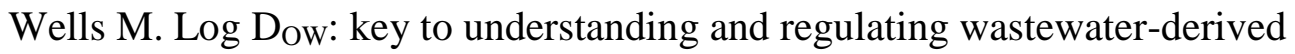
contaminants. Environ Chem 2006;3:439-49.

White M. FSS Report on Methylamphetamine: Chemistry, seizure statistics, analysis, synthetic routes and history of illicit manufacture in the UK and the USA., Forensic Science Service, UK; 2004.

Zuccato E, Castiglioni S, Bagnati R, Chiabrando C, Grassi P, Fanelli R. Illicit drugs, a novel group of environmental contaminants. Water Res 2008; 42 (4-5), 961-968. 